\title{
Rethinking Lynch's “The Image of the City” Model in the Context of Urban Fabric Dynamics. Case Study: Craiova, Romania
}

\author{
Amalia NIȚĂ $\check{*}^{*_{1}}$ \\ ${ }^{*}$ Corresponding author \\ ${ }^{1}$ University of Craiova, Faculty of Sciences, Department of Geography, Craiova, ROMANIA \\ $\triangle$ amalia.badita@gmail.com (1D https://orcid.org/oooo-0oo3-4790-5889 \\ DOI: 10.24193/JSSPSI.2021.7.02
}

https://doi.org/10.24193/JSSPSI.2021.7.02

K e y w o r d s: urban image, urban dynamics, mental maps, cognitive level, Kevin Lynch

\begin{abstract}
A B S T RACT
Due to the global market competition, urban transformations affected most cities which wanted to attract more economic and social resources. The level of urban perceptions and their representations as mental images occupy a more important role in obtaining a successful city. In this way it is created a space that is interesting and enjoyable, being also exposed to all the changes that are taking place due to the advances in architecture and infrastructure. This paper will focus on urban image assessment at the cognitive level using an adaptation of the Lynch method, by identifying the five elements in the urban space: paths, edges, districts, nodes, and landmarks, leading to imageability and legibility characterization of the image. In this realm, the case study of Craiova city serves as a model of urban evaluation and will be explored. Interviews were conducted with residents of the city to quantify their perception about the urban image elements. The obtained results of the urban image perception are mapped and will be analyzed with aerial images in order to determine the type of urban fabric that is dominant in the city, the fine grain or the coarse grain layout. The results show that the five elements of the Lynch image of the city can be easily mapped and assessed and that a mixture between fine grain and coarse grain is the best solution identified for the city. The paper concludes by outlining the importance of urban image along with other geographical studies in the sustainable planning and development of cities.
\end{abstract}

\section{INTRODUCTION}

Cities have been affected by the process of urban revitalization because they wanted to be included in the global market competition where they try to attract more economic resources and consolidate an important position, transforming their urban representations at the level of perceptions.

Thus, cities are located in places that maximize their ability to generate a social excess and to integrate economic activities within the activities of the rest of society (Berger, 1978). Some cities have chosen to remodel the urban spaces, projecting an image that attracts the visitor and the resident, but at the same time, they try to manage the problems and tensions associated with this process of urban fabric transformation. Cities are no longer just built; they are imagined and described (Vale and Warner, 2001).

The image of the city is increasingly exposed to recent advances and to changes in infrastructure. An urban landmark for the community, an element of the urban image in residents' perception, must adapt to the 
new functions and needs of the city and to become tool in the urban development processes. Thus, the city becomes defined by its urban image.

Spreiregen (1965) appreciates that the urban image consists of many architectural works put together or in chaos.

Some authors (cf. Appleyard, 1969) consider that the city elements can have pragmatic functions, but also symbolic and social meanings.

Until the 1980s, industry played an important role in urban planning, and influenced greatly the urban image. The post-industrial economy was based on the services sector which became the dominant activity in many states, and which redirected the investment in factories towards another sector of activity.

The way an area is perceived as well as its physical and environmental desirability will affect the investment of developers and companies, on the one hand, and the desire of employers and employees to live and work in that place, on the other hand (Watson, 1991).

Thus, cities redeveloped and regenerated their economies, landscapes, and images when they faced the stage of deindustrialization (Hall, 1998).

Many old industrial cities have a poor or problematic image, usually based on outdated perceptions of those places (Holcombe, 1993, cited by Law, 2002).

The components of the urban fabric (streets, squares, boulevards, etc.) are important in building the urban image because they provide inputs about city life. From one's own environment, each person builds his or her own mental image of the parts of the city that are physically related to each other and that overlap with those of other people, so that a collective image is formed about what people extract from the physical reality of the city, being in fact the urban image. The relevance of place is an important element when discussing about preserving heritage and boosting development (Banini and Ilovan, 2021a).

In addition to physical characteristics, place is also a lived value, a social unit that has many meanings and is influenced by people's experiences in time and space (Ersoy, 2002, cited by Law, 2002). The aesthetic experience influences the level of perception. That is why a more aesthetic urban environment will attract more people than one that is not very interesting (Topcu and Topcu, 2012).

The significance of the concept of urban image has often been confused with the notions of urban space, with the city itself, and also with urban architecture (Lynch, 1960, Garcia-Domenech, 2015, Almusaed and Almssad, 2019, Liu et al., 2020). However, its meaning has proved to be much more complex, and a proper definition was required.

The urban image is the simplified, generalized, stereotypical impression that people have about the city. It is almost impossible to know an entire city so that people reduce the complexity of reality to a few selective impressions, in fact to a few images of places that represent the physical, social, cultural, economic, and political characteristics. In the sphere of perceptions, the image is much more important than the reality, so that the urban image can be intelligently transformed by the marketers of the city without the need for a real intervention at the level of the urban space (Hall, 1998).

It is multidimensional, descriptive, and symbolic, "the urban image can be considered an integrative interface that mediates the conflict of perceptions and meanings of the urban space", it is in fact the relationship between "the physical, real city and human perception of it, the mental city" (Neaç̧u, 2010).

Every citizen associates with certain parts of the city, and this urban image stored in his or her memory has certain meanings, resulting a mental image of the space. It is precisely these meanings that are transposed into the urban elements that give the city an urban identity (Lynch, 1960). These images and knowledge compose cognitive maps, this being the first level of representation of an urban image.

The perception of space and the manifestation of mental images are mental phenomena. They involve the collection of data from outer space, their organization and processing at the cognitive level (Bilsel, 2002, cited by Law, 2002). In other words, the image of space embodies an individual image (Lynch, 1960).

Knowledge of the environment is strictly dependent on the interest and forms of user perception: Lynch (1960) specifies that some people first notice a market, while others only the public catering arrangements.

The representations of the identity of places emerge from images, discourses and social practices (Banini and Ilovan, 2021b).

After the perception process, the elements that have been perceived are stored in the mind in the form of images. The image is the first representation of the environment in the human brain and includes past and current experiences (Fig. 1).

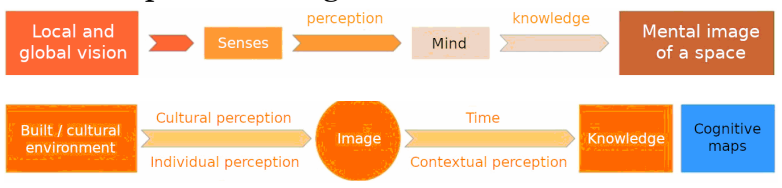

Fig. 1. The manifestation process of mental images and the formation of cognitive maps (source: adaptation after Page and Connell, 20O1; Topcu and Topcu, 2012).

The evaluation of the city image is a very important point when talking about city planning and marketing. It represents a key element of the city diagnosis and should serve as the basis for urban planning. Most of the times, the concept of urban image has a multidimensional approach, and, beside the urbanistic elements, it includes other elements that 
contribute to the forming of urban image (LuqueMartinez et al., 2007).

There are studies (cf. Priporas et al., 2020) that attempt to investigate young residents' (Zers-born from 1995-2009) engagement with the social media of cities in terms of city image and brand, and to present their satisfaction during various crisis periods.

New research is using new technologies, focusing on object detection and classification of urban images using technologies as complex background classification network (CBCNet), in which a detection sub-network is developed to recognize key information in urban images (Li et al., 2020).

Other studies are using Geo-coded Social Media, GIS database, and social-media (Instagramability, Twitterability) approaches to present the perception of city image from different perspectives: architectural landmark and tourist attractions and the relevance to the everyday life, all these having implications for urban planning (Huang et al., 2021).

The American urban planner Kevin Lynch (1960) launched the concept of urban image in his book "The Image of the City", which outlines a mental city according to the perceptions of urban actors, who can easily draw some characteristics of the urban area. They can identify the identity defining elements or the dysfunctions of the city itself, and they become actively involved in the changes taking place in the city. In the original method, 30 persons drew maps reflecting their perception of three American cities: Boston, New Jersey, and Los Angeles. The conclusion of the book was that an efficient way of mapping these perceptions, and implicitly of the urban image, can be achieved through the mental map, which, according to the same author, consists of five representative elements:

- districts (neighbourhoods), which represent unitary delimitations in the urban space, and which have own functional and visual characteristics;

- landmarks have certain functions, but also their own visual aspect and constitute important elements for the orientation within the urban space;

- edges are ruptures in space, real visual or physical barriers (watercourses, streets/ highways, areas with fences);

- paths - streets or pedestrian passages frequently circulated;

- nodes are spaces with a high social concentration (stations, urban markets, malls, intersections within the city, etc.).

Some authors consider that the city nodes, paths or districts are 'information carriers' and shape the mental image of the analysed urban space (Filomena et al., 2019). Since the first study of Lynch, his model was reinterpreted and adapted to the new technologies. With the availability of GPS technologies, followed by the geo-located applications for smartphones, the perception of space and even the cognitive mapping of cities have decreased in importance because the spatial orientation became less important when navigating with such tools (Thielmann, 2007). But some studies consider that the algorithmic city is full of the same elements as Lynch's abstracted city and propose a new examination of geospatial interfaces on the mental imaging of cities, and of how visible urban algorithmic processes should be when creating smart cities (Hamilton et al., 2014).

There are studies that still use the Lynch method, but with an impact of ICT (Information Communication Technologies): navigation, mapping, and location (a virtual reality and a visual reality) on the observer, inhabitants of the city, and the observed, the physical form of the city, and how these new instruments affect the perception of space (Al-ghamdi and Al-Harigi, 2015).

Some others (cf. Salerno, 2014) underline the fact that the Lynch model is still considered and has major results nowadays, especially when discussing urban redevelopment. The residents of the city must be consulted on various issues like urban identity, transportation, communication, but their interventions should be adapted to the new technologies that create an impact on the city.

Recently, there are studies that try to capture the idea of urban image through user generated content. The street segments are used as a natural unit to organize image metadata to reduce data aggregating issues, thus capturing semantic similarity, user behaviour and temporal patterns (Bahrehdar et al., 2020).

In various studies, the urban fabric is divided into two types: the coarse grain and the fine grain (Artibise, 2012; Price, 2017). The coarse grain on one hand defines places that are large-scale, functional but not comfortable, such as blocks, big stores, corporate centres, mega shopping areas. These single-purpose areas do not provide interconnection and become a barrier within the urban fabric.

The fine grain on the other hand represents an urban pattern with not too big blocks which are in proximity, areas that are easily navigable, with large intersections. The traffic is slower, there are no parking or empty lots. It is a space of evolution over time, preserving the initial identity and the architectural roots, responding at the same time to the residents' needs.

In American cities, the granularity of space is defining the development of an area. Older neighbourhoods encompass vibrant and walkable fabric with a variety of textures and buildings that contribute to an increased value of the city according to Rogers Merlino (2011). The plat is the most important in planning and this urban system is composed of two basic elements: the block, bounded by public streets, and the individual lots into which the block is divided. 
The fine-grained organization of the large buildings was also studied, allowing to design individually the units of the same building in order to create an 'open building' (Habraken, 2017).

Many older urban areas in the US or UK are normally fine-grained (EPOA, 2018). This urban fabric can evolve from residential area to mixed retail or to dense urban core, depending on the requirements of the urban development. Many times, the coarse-grained areas are the newer parts in a city and fail to evolve and develop over time especially when there is a single bigger economic tenant like shopping malls. A very different daily experience is created in the areas that are accessible on foot versus the auto-oriented areas.

When analysing the urban fabric, urban indicators are used in order to provide a multidisciplinary framework with social scientists, urban planners and policy makers who support the fine-grained approach and open data (Pileggi and Hunter, 2017).

Guyot et al. (2021) use the Multiple Fabric Assessment (MFA) for partitioning the urban fabric from the pedestrians' point of view in Brussels. They investigate the role of vegetation and areas devoted to pedestrians in the identification of urban fabric, vegetation playing a fundamental role in the description of residential neighbourhoods, while it has a less relevant role in defining the urban fabric in compact central areas.

GIS is used to identify urban fabric because it is a tool for planning the cities, and public transportation and commercial areas define the transit in this fabric (Helminen et al., 2020). Papers focus on developing privacy protection and data needs for finegrained urban traffic modelling applications using mobile sensors (Sun et al., 2013).

Spatial granularity and urban morphology at a fine-grained level are approaches in urban studies that present the organic street layouts with more or less compact forms, being necessary in the urban development (Li et al., 2016; Mottelson and Venerandi, 2020).

Fine-grained and organic form are taken into consideration when the spatial logics and urban circulation systems are studied (Boeing, 2021). The spatial patterns of different compositional grain are analysed in different cities, specifying the coarse grain with large units or the Lynchian fine grain unitary diversity within morphological urban coherence (Çalışkan and Mashhoodi, 2017).

This paper aims to present the cognitive level of urban image, using as case study a Romanian former industrial city. The method applied is a reinterpretation of the Lynch model. The main objectives of this research are: (1) to verify if the reinterpretation of Lynch's 'The Image of the City' model is a good determinant for the cognitive level of urban image in Craiova city, (2) to present the residents' perception of the five defining elements of the urban image according to the Lynch model, (3) to map residents' perception and to obtain a cognitive map of the urban image, (4) to identify the relation between the image and the urban fabric and to express how urban granularity makes an impact on the residents' minds and on urban development, creating a better outcome for the city.

This research showed that the urban image is important in the sustainable planning of the city along with other geographical studies and it needs to be included in future projects of urban development.

\section{METHODOLOGY}

The study on the perception and knowledge of urban space in Craiova was conducted using the cognitive level that is based on the classical model of $\mathrm{K}$. Lynch's city analysis (1960), which is reflected by the identification of the five elements in the urban space: paths, edges, districts, nodes, and landmarks by its residents. The urban image mapping was also achieved. The obtained image through this analysis can be easily connected with the type of urban fabric present in major cities, the so called fine-grained and coarsegrained fabric layout. The correlation between the image and the urban fabric leads to a better understanding of the residents' preferences for certain areas of the city and also shows the neglected areas that need some interventions in order to increase the attractiveness and the development level.

In this paper, the Lynch method was reinterpreted and adapted because, according to the original method, the respondents had to draw the city space taking into account the five basic elements, at the end resulting the cognitive maps of the city that reflect the inhabitants' perceptions. After sampling the urban respondents, in-depth interviews took place instead and the respondents had to answer questions regarding the five elements of the classical Lynch analysis. This was followed by the mapping process, which was not done by the respondents as in the classical method, but by the author, after processing all the information obtained from interviews.

For this research conducted in Craiova, the respondents were sampled randomly, resulting a total number of 138 residents that took part at the interviews during 2019 and 2020 (total population size of Craiova299,969 inhabitants in 2020, according to the National Institute of Statistics, confidence level of the sample $95 \%$ and margin of error $8.4 \%$ ). The socio-demographic characteristics show that 54 are males and 84 are females, 22 are below 25 years old and 116 are above 25 years old, 93 have a university degree, the majority work in the services sector and they have been living in Craiova for more than 10-25 years.

An interesting input in the study was the "granularity" approach of the urban fabric. The 
identified places of the urban image on the mental map obtained from the respondents are analysed with aerial images to identify the type of urban fabric (fine grain versus coarse grain layout) that creates a greater impact on the respondents' mind.

\section{RESULTS AND DISCUSSION}

\subsection{The case study - Craiova city}

Craiova is among the largest cities in Romania, being the county seat of Dolj, located in Oltenia region (in the south-west part of the country), on the eastern banks of the Jiu river. It is situated at $229 \mathrm{~km}$ from the capital city of Romania, Bucharest, and at $334 \mathrm{~km}$ from
Timişoara, the largest city in the western part of Romania.

Craiova recorded less than 300,000 inhabitants at the last census in 2011 and the urban space has a mixt profile, being a commercial and industrial centre. Before the 1990s, the city was known for its developed industrial sector which faced a deindustrialization process in the post-communist period. The city adapted to the new era of services that represent nowadays a large share in the economy of the city. Several companies in the city are large producers in the transportation and automotive sector and the largest public university from Oltenia is located in Craiova (Fig. 2).
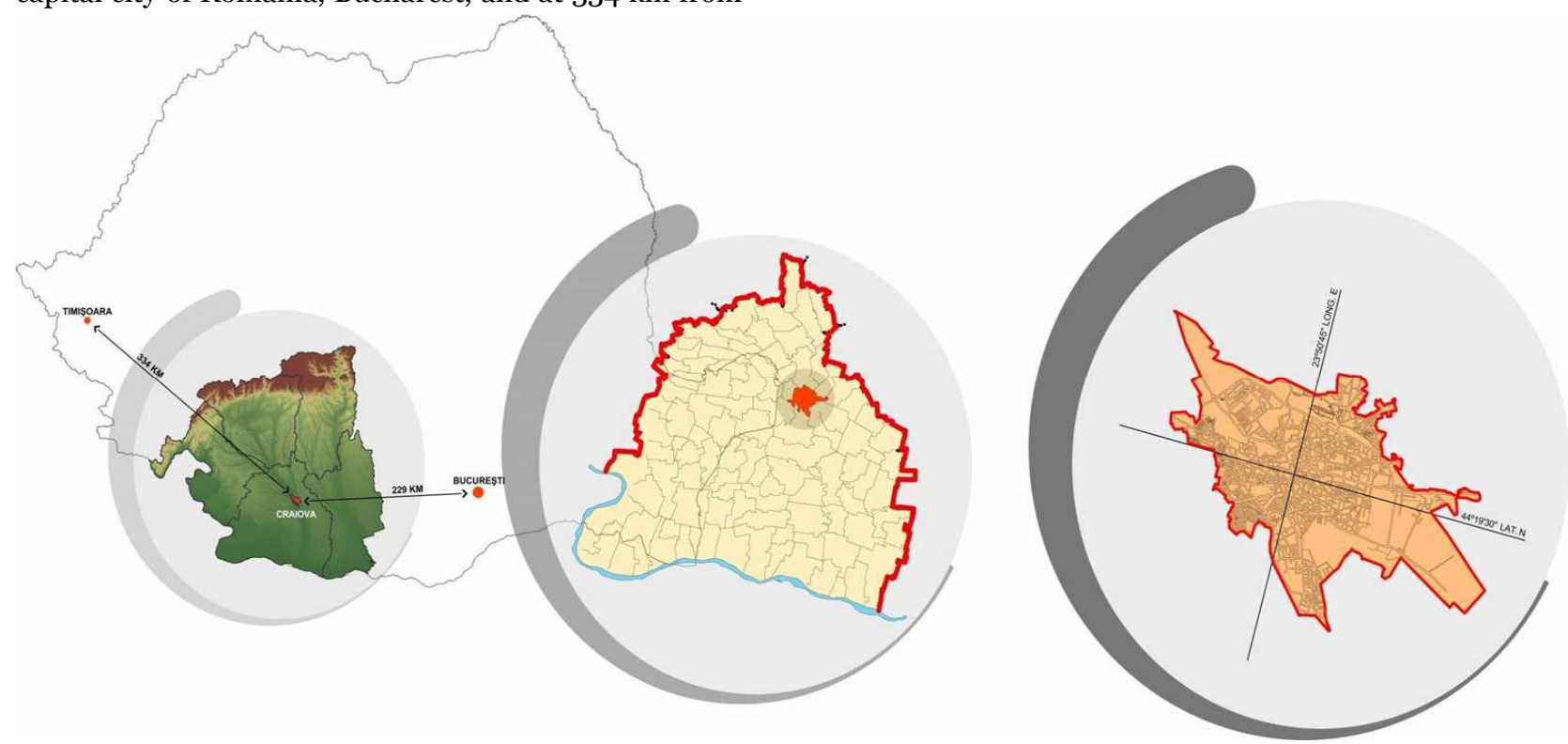

Fig. 2. Craiova city- geographical location at the national, regional, and county level.

\subsection{Urban image -cognitive level}

The mental-cognitive map aims to explain how residents form their mental images about the city space, more precisely the legibility and the imageability of the urban landscape will be determined. The in-depth interviews with the residents (see Methodology) focused on questions related to the five elements of the urban image described by Lynch.

The first question aimed at identifying the landmarks important in the residents' perception, according to the area where they live (Mention a spatial landmark in the district you live in/in Craiova). Several elements were outlined by respondents: the landmarks with architectural design impact, most of the respondents mentioning the statue of Mihai Viteazu [Michael the Brave] in Piața Prefecturii (County Hall Square) (70 respondents out of 138 considered this statue a historical symbol due to the prince's importance for the Oltenia region), the Jean Mihail
Palace, now an Art Museum (65 responses for this Baroque architectural building located in the city centre), the University of Craiova's main building (53 persons selected this building which hosted the Palace of Justice and was designed according to the French vision), the shopping centre in the western part of the city (29 respondents focused on this commercial area which is the biggest of the city, with shops of international brands), McDonalds, the stadium, The County Hospital, Ford Factory, the railway station, and the green areas: The Romanescu Park (52 residents named this largest urban green area in Romania designed by a French architect), The English Park, and The Botanical Garden, being the main green areas of the city with recreational value. In determining the nodes (Mention poles/zones of social concentration in the district where you live in) of the urban space of Craiova, many large intersections were identified by the respondents: the intersection at the University of Craiova (main building) - Carol I Avenue - Calea 
Bucureşti [Bucureşti Avenue] (82 respondents), the intersection of Lăpuş - Argeş streets - Calea București [Bucureşti Avenue] - Decebal Avenue (67 respondents) and the intersection of Calea Severinului [Severin Avenue] - Bulevardul Tineretului [Youth Avenue], but also squares, railway station, the mall: the railway station, Electroputere Park Mall, Piaţsa Mihai Viteazul [Michael the Brave Square], Central Open market, Valea Roşie [The Red Valley] Square, Craioviţa market, and Chiriac Square.

Regarding the paths, the streets with highest movement, respectively (Mention a street intensely circulated in the district where you live in), the residents outlined the polarizing axes of the city with inflows and outflows from the municipality (identified by 68 respondents): Calea București [Bucureşti Avenue], N. Titulescu Avenue, Calea Severinului [Severin Avenue], the paths from the city centre (47 residents chose them): A.I. Cuza Street, Lipscani pedestrian street, and the streets from different residential districts (23 respondents): Dacia Avenue, Amaradia and George Enescu Street, Bulevardul Tineretului [The Youth Avenue], Decebal Avenue, Caracal Street, Râului Street (River Street), Bulevardul Ştirbei Vodă [Prince Ştirbei Avenue], Brestei Street, 1 Mai [1 May] Avenue.

Regarding the edges that constitute physical or visual barriers (Mention a physical or visual barrier in the urban landscape of the district where you live in) most respondents identified the railway (44 respondents) as a break in the landscape and the overpass from the city centre (94 respondents), which determines a discontinuity and a segregation in the area where it was created, another edge was the underground passage near the university, identified by some respondents (17 respondents). In the delimitation of neighbourhoods or districts (Specify the neighbourhood in which you live in), it was observed that their names are known by the majority of the respondents although they have no clear delimitation of them. It should be noted, however, that many people (34 respondents), especially in the peripheral areas, did not mention the neighbourhood but the street where they live, so mapping their perceptions included only the central area and residential neighbourhoods: Brazdă, Rovine, 1 Mai [1 May], Valea Roşie [The Red Valley], Craiovița Nouă [New Craiovița]. Using the five elements highlighted by the residents' perceptions, the mental-cognitive map of the city was elaborated.

The Lynch method concludes with the particularization of two concepts:

- the legibility, a term that expresses the degree of clarity of the urban landscape meaning the easiness of identifying any part of a city, easy orientation within it, its quick "reading", the image being organized in a coherent and clear model, providing emotional confidence, increasing the density of experiences, and decreasing the state of chaos, anger, and unconsciousness in space (Lynch, 1960). In Craiova, being given the relatively easy identification of different parts of the city through the five elements, the "reading" of the city can be done quickly because of the ease of navigation and orientation. Thus, the urban image of the city is organized in a relatively coherent and clear model, this fact offering an increased emotional confidence to its residents that have no feelings of getting lost in the city.

- the imageability, which refers to the quality of a city to provoke the perception of a strong image to the external observer. In addition to the visual feature, the identity is very important. An urban place considered well-functioning can be mentally mapped very easily because it has an easy-to-remember spatial organization. Craiova does not exert an extremely strong visual impact on observers although most of the visual characteristics are located in the city centre and fewer are found in the residential areas. The imageability is difficult to be defined. Given the diversity of elements in the urban space that were mentioned as landmarks, the mental mapping was difficult to be achieved. The spatial organization of the city is not so easy to remember, appearing some disruptions especially in certain peripheral areas (Fig. 3).

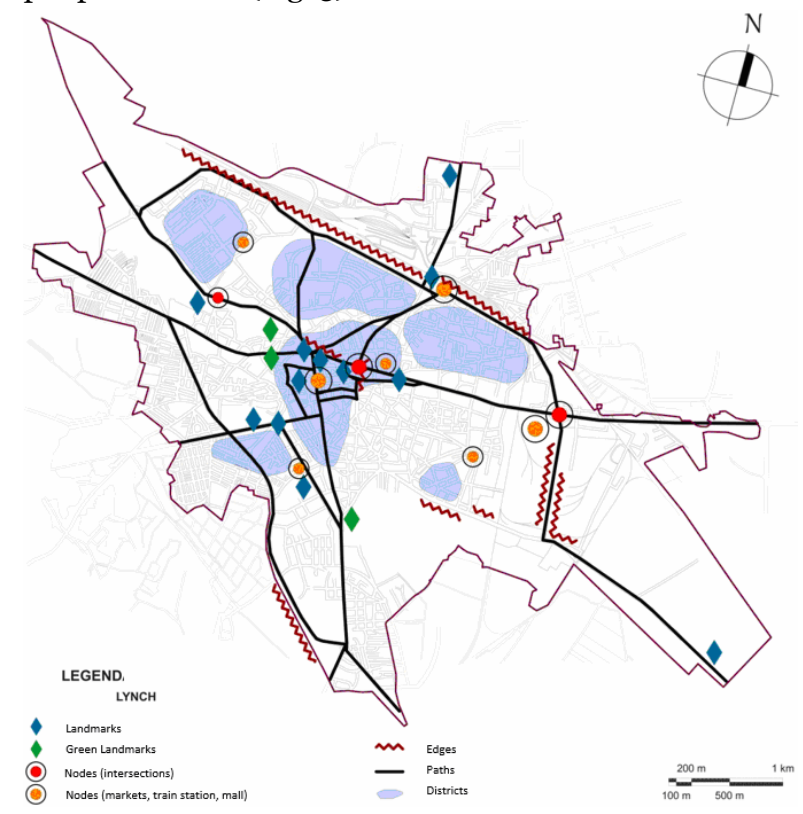

Fig. 3. The cognitive mental map of the urban image in Craiova - Lynch analysis.

\subsection{Urban fabric characteristics}

After the analysis of the aerial images of the main places identified on the mental map by the residents of Craiova, it is easy to conclude that the older urban parts located in the city centre are typically finegrained. In contrast, the newer parts of the city (the extremities), especially the industrial platforms are coarse-grained. The residential areas became a mixture 
of fine- and coarse-grained. Somehow the pattern of Craiova overlaps the European and the U.S. granularity patterns.

In recent years there was a trend to define the urban image through special events that are organised in the city or through iconic architecture. The relation between events and host city image perceptions were discussed by Oshimi and Harada (2019). They identify the outcome of city image perceptions and its impact on the behaviour toward the event, concluding that the residents are ambassadors of the event and the place

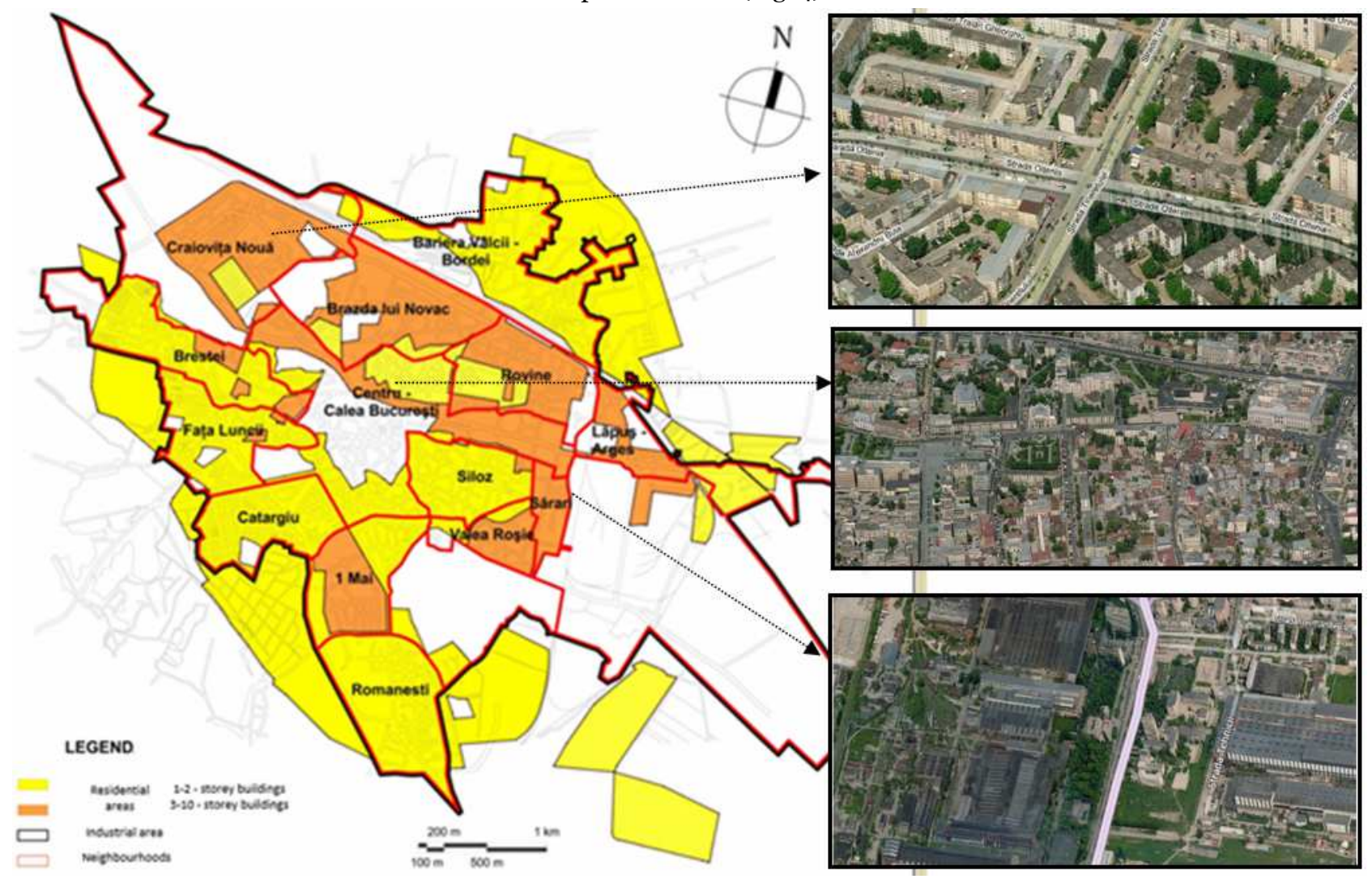

attachment is the main impact of the event on the host city. Some national and international festivals such as Shakespeare International Theatre Festival or Maria Tănase Traditional Music Festival bring many visitors and improve the perceptions of the city.

In Craiova, the $19^{\text {th }}$ century was a period of large buildings, classic houses with ornaments, palaces that are clear landmarks even at present. In the $20^{\text {th }}$ and $21^{\text {st }}$ centuries, classical architecture loses significance and modern buildings appear in the city (Fig. 4).

Fig. 4. The fine-grained and coarse-grained urban fabric in Craiova (upper aerial image-residential district in the north-west of the city-fine-grained; middle image-old urban city centre, mixture of fine- and coarse-grained urban fabric; lower imageindustrial platform in the east of the city, coarse-grained fabric) (source of aerial images: Bing maps).

The centre of the city, characterized by finegrained fabric that sometimes interferes with coarsegrained fabric, has the highest impact on the residents who outlined very clearly this fact in the urban image. The two major activities - business and commerce - are located in the city centre, but sometimes they are subject to decentralization to peripheral areas, although some areas as law, finance and services tend to remain in the city centre due to accessibility and direct contact with collaborators. The commerce in the city centre has to become more specialized in order to survive in the competition with the trade from the mall located at the periphery. The interviews conducted in Craiova revealed that the group of adults and young people with higher incomes, who go to bars and clubs, relate more with the centre in comparison to the elderly group with a lower share that go very rarely to restaurants and theatre in this part of the city. Thus, if the city centre is more accessible and livelier, it will attract even more people from different age groups in this part of the city.

In Craiova, as in most cities in Romania, the pattern of paths and how the residents move between districts evolved. The newer urban parts lack sometimes the uniformity in the layout of public spaces and routes and the accessibility of pedestrians is not convenient. The fine-grained fabric was altered starting from the city centre or residential areas near it by the commerce and the services that need to have also parking lots and conveys the space into a coarse-grained pattern. It is observed that despite all changes that occurred, the 
centre and some residential neighbourhoods are finegrained, characterized by an intense movement. In contrast, the areas with lower agglomeration have a coarse-grained fabric (the industrial platforms at the extremities of the city). Sometimes it occurs that a neighbourhood gets altered and becomes coarsegrained by the insertion of commercial buildings.

The European models show that the best approach in this case is development by extending an existing fine-grained pattern and creating paths that are connected to others. The streetscape and even the economic tendencies play an important role when talking about the restructuring or the development of an urban area.

\section{CONCLUSIONS}

Craiova, a former industrial city, has an important number of heritage buildings, landmarks, and services which can represent the potential for future urban development. The current development process focuses mainly on the promotion of commercial facilities and on the attempt to attract young professionals, tourists, and students to the city. Craiova tries to discover in this way a new identity and to strengthen its role in the economic and social system of Romania. Thus, the future direction of city development involves an integrative approach of a proper urban revitalization and development.

The actual identification of the urban image role in the urban dynamics represents a real tool in the assessment of the quality of the space, because the five elements of the urban images can be used in the process of urban restructuring or in the mitigation of intraurban inequalities.

In terms of urban fabric, the case study shows the advantages of fine-grained urbanism. In this case, the space is formed of divided lots that have different owners, which are cheaper and offer many services (offices, shops, flats) that are fitted within walking distance. This is the case of the city centre. In contrast, the coarse-grained areas need normally more investments, have high maintaining costs and they are considered bad buildings that are large, with single service and do not fit in the streetscape, affecting negatively the urban landscape. This is the case of the peripheral areas of Craiova, such as the commercial centres and the industrial platforms.

This coarse-grained fabric is sometimes a necessity as schools, supermarkets or factories need more space to be built, but used in moderation and integrated harmoniously in the urban space, will not lead to areas that are not considered interesting and attractive for residents. The practice shows that smaller lots of land will increase the chances to obtain a finegrained urban fabric, where buildings with different functions can be obtained instead of having large surfaces that are built with one purpose buildings which are not attractive.

In order to create a better place with an attractive urban image among the residents, a finegrained environment can be the ideal solution from an economic and urbanistic point of view. Sometimes a good and achievable solution can be also the mixture of urban fabrics, fine and coarse grain, bringing together the businesses, residential areas and green ones in a successful and strong urban image (as in the case of some residential areas and the spaces near the city centre of Craiova).

The urban transformations of areas, by proposing appropriate new functions, allows the preservation and the remodelling of the urban areas. Urban identity is being used as a catalyst for promoting the space and for creating its image. The urban image represents for each city an asset that might be integrated successfully within the urban planning, for proper reuse and functional conversion of space, contributing to the enhancement of places and their identity.

Further studies of the urban image will be carried out focusing on the evaluative level of the space, trying to determine the most attractive or repulsive places in the city. After the recognition of the main identity defining elements of the image, an evaluation of their capacity can determine new approaches in the study of the image of the cities.

\section{REFERENCES}

Al-ghamdi S. A., Al-Harigi F. (2015), Rethinking image of the city in the information age. Procedia Computer Science 65, 734-743, DOI: https://doi.org/10.1016/j.procs.2015.09.018

Almusaed A., Almssad A. (2019), City phenomenon between urban structure and composition. In: Almusaed A., Almssad A., Truong-Hong L. (eds.), Sustainability in Urban Planning and Design, IntechOpen. DOI: 10.5772/intechopen.90443

Appleyard D. (1969), Why buildings are known. Environment and Behavior, 1(2), 131-156, DOI: https://doi.org/10.1177/001391656900100202

Artibise Y. (2012), What is urban fabric? [online]. URL: $\quad$ http://rethinkurban.com/2012/places-andspaces/understanding-urban-forms/. Accessed on 11.01.2021.

Bahrehdar A. R., Adams B., Purves R. S. (2020), Streets of London: Using Flickr and OpenStreetMap to build an interactive image of the city. Computers, Environment and Urban Systems, 84,101524, DOI: https://doi.org/10.1016/j.compenvurbsys.2020.101524 Banini T., Ilovan O.-R. (2021a), Conclusions: towards a new agenda for place/territorial identity research. In: Banini T., Ilovan O.-R. (eds.), Representing Place and Territorial Identities in Europe. GeoJournal Library, vol. 
127. Springer, Cham, 251-265, DOI: https://doi.org/10.1007/978-3-030-66766-5_17

Banini T., Ilovan O.-R. (2021b), Introduction: dealing with territorial/place identity representations. In: Banini T., Ilovan O.-R. (eds.), Representing Place and Territorial Identities in Europe. GeoJournal Library, vol. 127. Springer, Cham, 1-19. https://doi.org/10.1007/978-3030-66766-5_1

Berger A. S. (1978), The City. Urban communities and their problems. Brown Company Publisher, Cincinnati. ISBN-10: 0697075559

Boeing G. (2021), Spatial information and the legibility of urban form: Big data in urban morphology. International Journal of Information Management, vol. 56, 102013, DOI: https://doi.org/10.1016/j.ijinfomgt. 2019.09.009

Çalışkan O., Mashhoodi B. (2017), Urban coherence: a morphological definition. Urban Morphology, 21(2), 123-41, ISSN: 1027-4278

EPOA (2018), Design details in Essex design guide (Essex Planning Officers Association), https://www.essexdesignguide.co.uk/design-

details/layout-details/urban-grain/. Accessed on 21.11.2020

Filomena G., Verstegen J. A., Manley E. (2019), A computational approach to 'The Image of the City', Cities, $\quad 89$, 14-25. DOI: https://doi.org/10.1016/j.cities.2019.01.006

Garcia-Domenech S. (2015), Urban aesthetics and social function of actual public space: a desirable balance. Theoretical and Empirical Researches in Urban Management, 10(4), 54-65.

Guyot M., Araldi A., Fusco G., Thomas I. (2021), The urban form of Brussels from the street perspective: the role of vegetation in the definition of the urban fabric. Landscape and Urban Planning, 205(2), 103947. DOI: https://doi.org/10.1016/j.landurbplan.2020.103947

Habraken J. (2017), Back to the future: the everyday built environment in a phase of transition. Architectural Design, $\quad 87(5), \quad 18-23 . \quad$ DOI: https://doi.org/10.1002/ad.2211

Hall T. (1998). Urban Geography, 3rd Edition. Routledge Contemporary Human Geographies Series. London. ISBN: 9780415344463.

Hamilton K., Karahalios K., Sandvig C., Langbort C. (2014), The image of the algorithmic city: a research approach. Interaction Design and Architecture(s), 20, 61-71.

Helminen V., Tiitu M., Kosonen L., Ristimäki M. (2020), Identifying the areas of walking, transit and automobile urban fabrics in Finnish intermediate cities. Transportation Research Interdisciplinary Perspectives, 8, $100257 . \quad$ DOI: https://doi.org/10.1016/j.trip.2020.100257

Huang J., Obracht-Prondzynska H., Kamrowska -Zaluska D., Sun Y., Li L. (2021), The image of the
City on social media: a comparative study using "Big Data" and "Small Data" methods in the Tri-City Region in Poland. Landscape and Urban Planning, 206, 103977.

DOI:

https://doi.org/10.1016/j.landurbplan.2020.103977

Law C. M. (2002), Urban Tourism: The Visitor Economy and the Growth of Large Cities. Second Edition. Continuum Publisher, London. ISBN: o82644928X

Li X., Lv Z., Hijazi I. H., Jiao H., Li L., Li K. (2016), Assessment of urban fabric for smart cities. IEEE Access, 4, 373-382, DOI: 10.1109/ACCESS.2016.2517072

Liu Z., Li Z., Li L., Yang H. (2020), Complex background classification network: A deep learning method for urban images classification. Computers \& Electrical Engineering, 87, 106771, DOI: https://doi.org/10.1016/j.compeleceng.2020.106771

Lynch K. (1960), The Image of the City. MIT Press, Cambridge, MA. ISBN: 9780262620017

Luque-Martínez T., Del Barrio-García S., Ibáñez-Zapata J. A., Rodríguez Molina M. A. (2007), Modeling a city's image: the case of Granada. Cities, 24(5), 335-352. DOI: https://doi.org/10.1016/j.cities.2007.01.010

Mottelson J., Venerandi A. (2020), A fine-grain multi-indicator analysis of the urban form of five informal settlements in East Africa. Urban Science, 4(3), 31. DOI: https://doi.org/10.3390/urbansci4030031

Neacşu M. C. (2010), Imaginea urbană. Element esenţial în organizarea spaţiului (The Urban Image. Essential Element in the Organization of Space). Editura Pro Universitaria, Bucureşti (Book in Romanian). ISBN: 978-973-129-550-3

Oshimi D., Harada M. (2019), Host residents' role in sporting events: The city image perspective. Sport Management Review, 22(2), 263-275, DOI: https://doi.org/10.1016/j.smr.2018.04.002

Page S., Connell J. (2001), Tourism: A Modern Synthesis. Thomson Learning, London. ISBN: 1861526407

Pileggi S. F., Hunter J. (2017), An ontological approach to dynamic fine-grained urban indicators. Procedia Computer Science, 108, 2059-2068. DOI: https://doi.org/10.1016/j.procs.2017.05.003

Price A. (2017), Fine-Grained vs. Coarse-Grained Urbanism [online]. URL: https://www.strongtowns.org/journal/2017/10/31/fine -grained-vs-coarse-grained-urbanism. Accessed on 2.02.2021.

Priporas C. V., Stylos N., Kamenidou I. (2020), City image, city brand personality and generation $\mathrm{Z}$ residents' life satisfaction under economic crisis: predictors of city-related social media engagement. Journal of Business Research, 119, 453-463, DOI: https://doi.org/10.1016/j.jbusres.2019.05.019. 
Rogers Merlino, K. (2011), Urban grain and the vibrancy of older neighborhoods: metrics and measures. In the Proceedings for ARCC 2011 -Considering Research: Reflecting upon current themes in Architectural Research, pp. 477-488.

https://core.ac.uk/download/pdf/295185354.pdf. Accessed on 2.02.2021.

Salerno R. (2014), Rethinking Kevin Lynch's Lesson in Mapping Today's City. In: Contin A., Paolini P., Salerno R. (eds.), Innovative Technologies in Urban Mapping. Built Space and Mental Space, Springer Chapter: II, Part 1.

Spreiregen P. D. (1965), Urban Design: the architecture of towns and cities. McGraw-Hill Publisher, New York.

Sun Z., Zan B., Ban X., Gruteser M. (2013), Privacy protection method for fine-grained urban traffic modeling using mobile sensors. Transportation Research Part B: Methodological, 56, 50-69, DOI: https://doi.org/10.1016/j.trb.2013.07.010.
Thielmann T. (2007), 'You Have Reached Your Destination!' Position, Positioning and Superpositioning of Space through Car Navigation Systems. Social Geography, 2(1), 63-75, DOI: 10.5194/sgd-2-27-2006

Topcu K. D., Topcu M. (2012), Visual presentation of mental images in urban design education: cognitive maps. Procedia - Social and Behavioral Sciences, 51, 573-582. DOI: 10.1016/j.sbspro.2012.08.208

Vale L., Warner S. B. (2001), Imaging the city: continuing struggles and new directions. New Jersey: Center for Urban Policy Research. ISBN: 978o882851709.

Watson S. (1991), Gilding the smokestacks: the new symbolic representations of deindustrialized regions. Environment and Planning - Society and Space, 9(1), 59-70. DOI: https://doi.org/10.1068/do90059. 